\title{
Retraction Note: Erratum to: Cuckoo optimization algorithm for unit production cost in multi-pass turning operations
}

\author{
Mohamed Arezki Mellal ${ }^{1}$ Edward J. Williams ${ }^{2,3}$
}

Published online: 29 March 2017

(C) Springer-Verlag London 2017

This article was published with the incorrect author names. Instead of Mohamed Arezki Mellal and J.Williams, the article should have identified its authors as A. Costa A and S. Fichera. A corrected version of this note will be published in the journal. Springer would like to apologise for any inconvenience caused.

This article was published with the incorrect author names. Instead of Mohamed Arezki Mellal and J. Williams, the article should have identified its authors as A. Costa A and S. Fichera. A corrected version of this note will be published in the journal. Springer would like to apologise for any inconvenience caused.

The online version of this article contains the full text of the retracted article as electronic supplementary material.

The online version of the original article can be found at http://dx.doi. org/10.1007/s00170-014-6309-2

Electronic supplementary material The online version of this article (doi:10.1007/s00170-017-0314-1) contains supplementary material, which is available to authorized users.

Mohamed Arezki Mellal

mellal.mohamed@gmail.com; mellal-mohamed@umbb.dz

1 Faculty of Engineering Sciences (FSI),

M'Hamed Bougara University, Boumerdes 35000, Algeria

2 Industrial and Manufacturing Systems Engineering Department, College of Engineering and Computer Science,

University of Michigan, Dearborn 48126, USA

3 Decision Sciences, College of Business, University of Michigan, Dearborn 48126, USA 